07

\title{
Динамика разрушения гетерогенного тела (диорита) при трении
}

\author{
(С) В.И. Веттегрень ${ }^{1}$, А.В. Пономарев ${ }^{2}$, И.П. Щербаков ${ }^{1}$, Р.И. Мамалимов ${ }^{1}$ \\ ${ }^{1}$ Физико-технический институт им. А.Ф. Иофрфе РАН, \\ Санкт-Петербург, Россия \\ ${ }^{2}$ Институт фризики Земли им. О.Ю. Шмидта РАН, \\ Москва, Россия \\ E-mail: Victor.Vettegren@mail.ioffe.ru
}

(Поступила в Редакцию 27 марта 2017 г.)

\begin{abstract}
При трении друг о друга двух образцов гетерогенного материала - диорита наблюдаются вспышки триболюминесценции. Она возникает при релаксации возбуждения свободных радикалов $\equiv \mathrm{Si}-\mathrm{O \bullet}$, ионов $\mathrm{Fe}^{3+}$ и захвата электронов акцепторными ловушками, образующимися при разрушении кристаллической решетки плагиоклаза. Анализ временной зависимости вспышек показал, что на трущихся поверхностях накапливаются кластеры, концентрация свободных радикалов $\equiv \mathrm{Si}-\mathrm{O} \bullet$ и ловушек электронов в которых, по крайней мере, на порядок, чем в их окружении. Временной интервал между появлением двух последующих кластеров изменяется от 0.1 до $1 \mu \mathrm{s}$. Линейные размеры кластеров составляют $\sim 0.5 \mu \mathrm{m}$.
\end{abstract}

Работа выполнена при финансовой поддержке Российского фонда фундаментальных исследований (грант № 16-05-00137).

DOI: 10.21883/FTT.2017.11.45072.093

\section{1. Введение}

Согласно современным представлениям [1,2], в основе механизма землетрясений лежит неустойчивость скольжения земных плит. Экспериментальные исследования строения природных поверхностей горных пород, образующихся после скольжения, было начато в работах [3-11]. Используя методы инфракрасной, рамановской и фотолюминесцентной (PL) спектроскопии, авторы установили, что химическое строение поверхностных слоев горных пород после скольжения отлично от строения их объема. Было предположено, что эти изменения вызваны разрушением пород под действием нормальных и касательных напряжений при трении. Чтобы проверить это предположение в [11] использовали метод триболюминесценции (TL). Образцом для исследований являлся рифейский (т. е. образовавшийся от 1650 до 650 млн лет тому назад) песчаник (RS). Было установлено, что при трении RS разрываются SiOSi связи в кристаллических решетках кварца и полевого шпата, входящих в состав этих пород.

Настоящая работа продолжает цикл этих исследований. Ее цель изучить динамику разрывов SiOSi связей в другой горной породе - диорите.

\section{2. Объект и методы исследования}

Образцом для исследования служил кварцевый диорит, добытый в одной из скважин Воронежского кристаллического массива, с глубины $\sim 100 \mathrm{~m}$. Он содержал зерна плагиоклаза - 30-40\% и кварца - 20-30\% и других минералов.
На рис. 1 показан фрагмент фотографии зерна плагиоклаза на поверхности исследованного образца после компьютерной обработки. Она позволила выявить границы блоков внутри зерна. Средний размер блоков составил $\sim 100 \mu \mathrm{m}$.

Для исследования динамики трения использована установка, описанная в [11]. Она состоит из вращающегося диска (диаметр - $83 \mathrm{~mm}$, толщина $13 \mathrm{~mm}$ ) и прижатого к нему стержня (длина $45 \mathrm{~mm}$, диаметр $9.5 \mathrm{~mm}$ ). Линейная скорость вращения диска $v_{d}=10 \mathrm{~m} / \mathrm{s}$. Давление стержня на диск - $1 \mathrm{MPa}$.

Оказалось (см. ниже), что трение диска о стержень привело к возникновению триболюминесценции (TL).

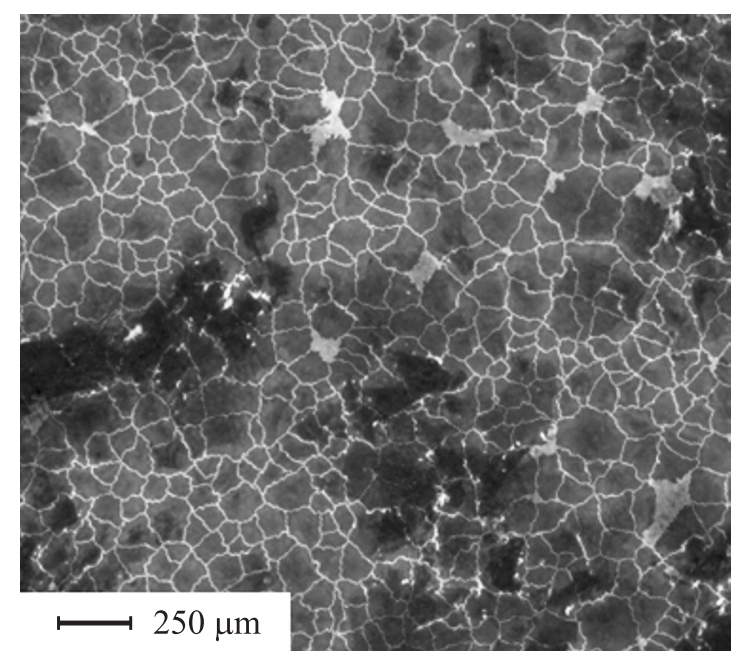

Рис. 1. Фотография зерна полевого шпата. Белые линии границы между блоками. 
Спектр TL регистрировали с помощью оптоволоконного спектрометра AvaSpec-ULSi2048L-USB2 OE.

Излучение, возникающее при трении, кварцевым световодом подавалось на поверхность фотоэлектронного умножителя РЕМ 136, а с него - на вход аналоговоцифрового преобразователя ADS-3112. Сигнал с выхода ADS с временны́м разрешением $2 \mathrm{~ns}$ записывался в память компьютера для дальнейшей обработки и хранения.

При трении диск и стержень нагреваются. Чтобы оценить температуру в зоне трения, вдоль оси стержня был пропилен паз глубиной $\sim 1 \mathrm{~mm}$ и в него вставлена термопара. Перемещая термопару внутри паза, измеряли температуру стержня $T(x)$ на различных расстояниях $x$ от зоны трения. (Установка для определения температуры описана в [8]). В стационарных условиях температура $T(x)$ связана с температурой $T(0)$ в зоне трения выражением (уравнение Пуассона) [12]

$$
T(x)=T(0)-\frac{F(x)}{\lambda} x,
$$

где $F(x)$ - плотность теплового источника, а $\lambda-$ коэффициент теплопроводности. В соответствии с этим уравнением зависимость температуры от расстояния оказалась близкой к линейной (рис. 2). Экстраполируя ее к $x=0$, нашли температуру в зоне трения $-\sim 150 \mathrm{C}$.

\section{3. Спектр TL, возникающий при трении диорита}

Спектр излучения при трении диорита (рис. 3) образуется при наложении друг на друга 3 ,элементарных“ полос, имеющих гауссову форму [13]: 1.39, 1.63 и $1.92 \mathrm{eV}$.

Полоса $1.92 \mathrm{eV}$ приписана возбужденным свободным радикалам $\equiv \mathrm{Si}-\mathrm{O}^{-}$[14-16]. Эти радикалы образуются при разрывах химических связей $\mathrm{Si}-\mathrm{O}-\mathrm{Si}$ в кристаллических решетках плагиоклаза и кварца. Максимум $\sim 1.63 \mathrm{eV}$ приписан возбужденным ионам $\mathrm{Fe}^{3+}$ [17], энергия которым передается от радикалов $\equiv \mathrm{Si}-\mathrm{O}^{-}[13]$. Полоса $1.39 \mathrm{eV}$ возникает при захвате электронов акцепторными ловушками в решетке плагиоклаза [18-20]. Вероятно, это ионы $\mathrm{Si}^{+}$, образующиеся после разрыва $\mathrm{SiOSi-связей.}$

Далее, для краткости, совокупность возбужденных свободных радикалов $\equiv \mathrm{Si}-\mathrm{O}^{-}$, ионов $\mathrm{Fe}^{3+}$ и электронов, взаимодействующих с положительно заряженными ионами, мы будем называть центрами люминесценции. Суммарная интенсивность полос, соответствующих центрам, пропорциональна концентрации разорванных $\mathrm{Si}-\mathrm{O}-\mathrm{Si}$ связей. Воспользуемся этим и изучим временну́ю зависимость концентрации разрывов.

\section{4. Динамика TL}

Фрагмент временной зависимости интенсивности TL показан на рис. 4. Она представляет собой набор вспышек, интенсивность которых варьирует по крайней мере на порядок, а временной интервал между ними от нескольких десятков - сотен ns.

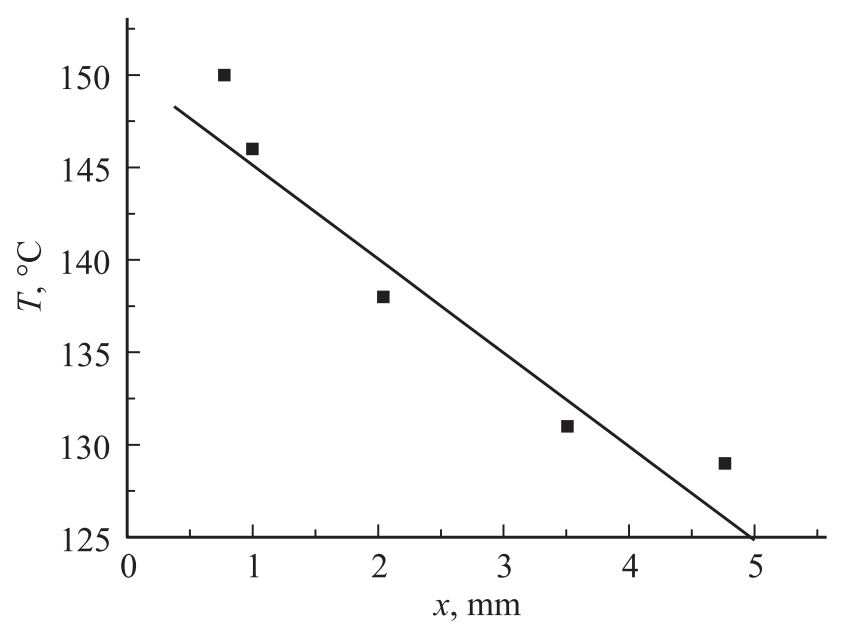

Рис. 2. Зависимость температуры от расстояния до зоны трения.

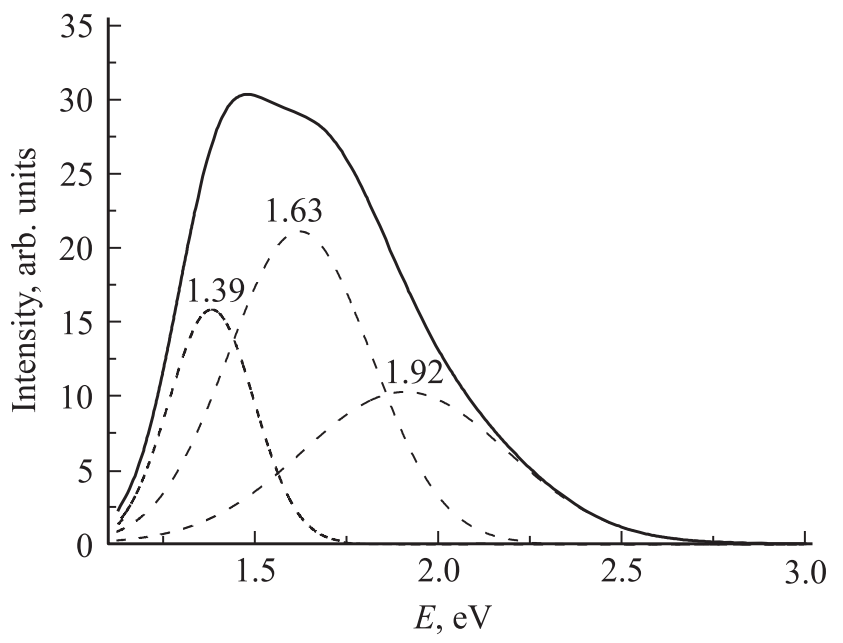

Рис. 3. Спектры излучения диорита при трении. Жирной линией показан измеренный спектр, „элементарные“ полосы 1.92, 1.63 и $1.39 \mathrm{eV}$ показаны штриховыми линиями.

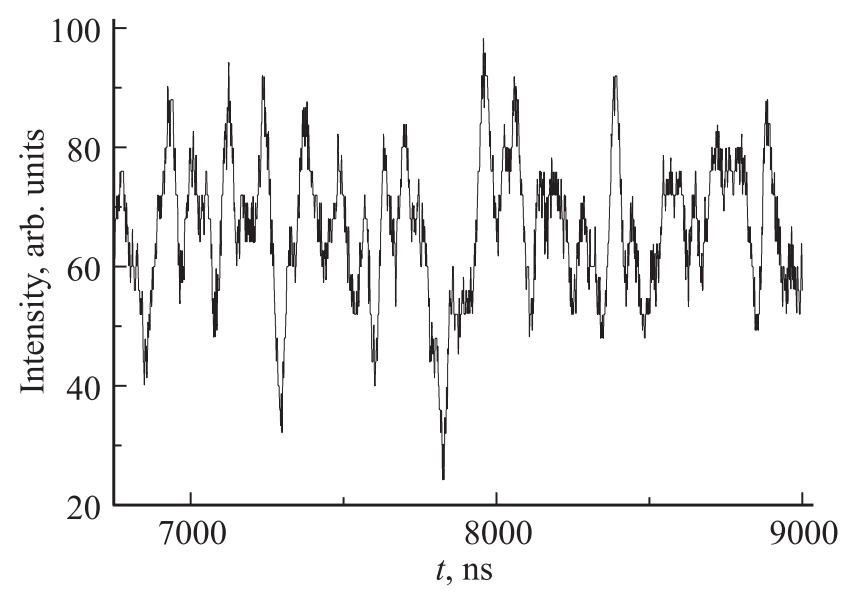

Рис. 4. Фрагмент временно́й зависимости интенсивности TL при трении диорита. 


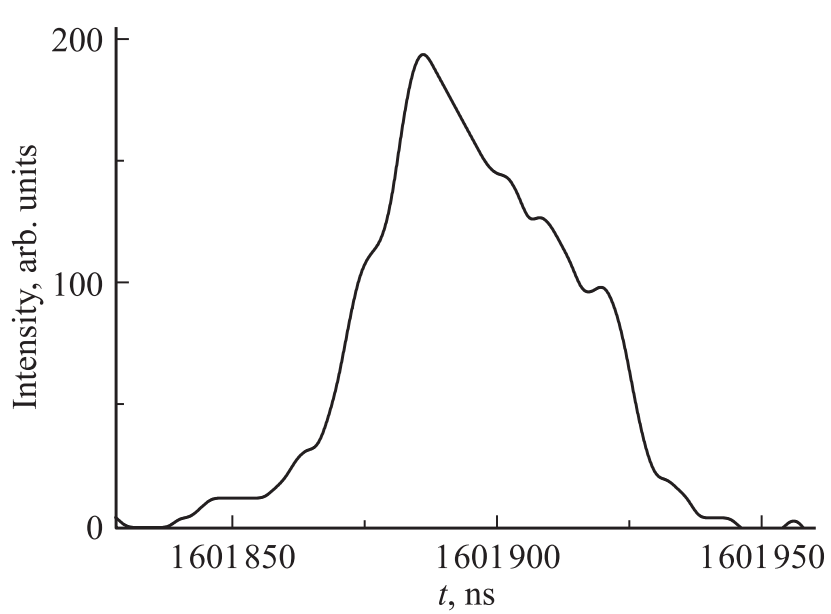

Рис. 5. Типичная вспышка TL при трении диорита.

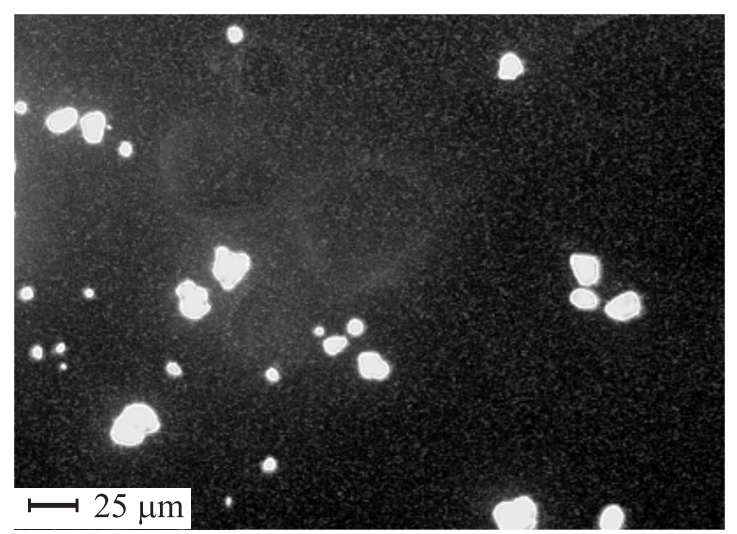

Рис. 6. Фотография частиц порошка, образовавшегося при трении диорита.

За время регистрации - $2 \mu$ s наблюдали появление несколько сотен тысяч вспышек. Одна из них показана на рис. 5.

Временна́я зависимость интенсивности вспышки задана скоростями образования и дезактивации центров люминесценции и скоростью уменьшения сигнала от РЕМ после прекращения свечения (определяемой величинами паразитной емкости и сопротивления нагрузки).

Вначале, когда число центров мало, скоростью их дезактивации можно пренебречь. Тогда из рассмотрения рис. 5 следует, что вначале концентрация таких центров растет. В максимуме вспышки скорость образования центров приблизительно равна скорости их дезактивации. Затем скорость образования центров становится меньше скорости деактивации и интенсивность люминесценции со временем уменьшается.

Среднее время существования вспышек - $50 \mathrm{~ns}$. Как уже упоминалось, скорость вращения диска $v_{d}=10 \mathrm{~m} / \mathrm{s}$, и за $50 \mathrm{~ns}$ его поверхность смещается на $\sim 0.5 \mu \mathrm{m}$, что на два порядка меньше среднего размера кристаллов плагиоклаза $(100 \mu \mathrm{m})$. Это позволяет предположить, что блоки в зернах плагиоклаза дробятся на частицы размерами на один-два порядка меньше размеров блоков. Чтобы убедиться в этом фотографировали частицы порошка (рис. 6), образующиеся при трении, и определяли их размеры. Оказалось, что их размеры составляют 5-20 $\mu \mathrm{m}$, что от 5 до 20 раз меньше линейных размеров кристаллов плагиоклаза.

\section{5. Заключение}

Зерна диорита содержат блоки с линейными размерами $\sim 100 \mu \mathrm{m}$. При трении блоки разрушаются, что приводит к появлению кластеров, содержащих свободные радикалы $\equiv \mathrm{Si}-\mathrm{O} \bullet$ и ловушки электронов. Размеры кластеров - $0.5 \mu \mathrm{m}$. Временной интервал между появлением двух последующих кластеров изменяется от 0.1 до $1 \mu \mathrm{s}$.

\section{Список литературы}

[1] J.H. Dietrich. J. Geophys. Res. 77, 3690 (1972).

[2] C.H. Scholz. The mechanics of earthquakes and faulting. $2^{\text {nd }}$ ed. Cambridge University Press, Cambridge. (2002). 471 p.

[3] Г.А. Соболев, В.И. Веттегрень, С.М. Киреенкова, В.Б. Кулик, Ю.А. Морозов, А.И. Смульская. Физика Земли. 6, 7 (2007).

[4] Г.А. Соболев, С.М. Киреенкова, Ю.А.Морозов, А.И. Смульская, В.И. Веттегрень, В.Б. Кулик, Р.И. Мамалимов. Физика Земли. 9-10, 17 (2012).

[5] Г.А. Соболев, В.И. Веттегрень, С.М. Киреенкова, В.Б. Кулик, Р.И. Мамалимов, Ю.А. Морозов, А.И. Смульская, И.П. Щербаков. Нанокристаллы в горных породах. ГЕОС, M. (2016). $102 \mathrm{c}$.

[6] В.И. Веттегрень, А.В. Пономарев, Г.А. Соболев, И.П. Щербаков, Р.И. Мамалимов, В.Б. Кулик, А.В. Патонин. ФТТ 59, 569 (2017).

[7] В.И. Веттегрень, В.С. Куксенко, И.П. Щербаков. ЖТФ 81, 4, 148 (2011).

[8] В.И. Веттегрень, В.С. Куксенко, И.П. Щербаков. ФТТ 54, 7, 1342 (2011).

[9] В.И. Веттегрень, В.С. Куксенко, Р.И. Мамалимов, И.П. Щербаков. Физика Земли. 5, 58 (2012).

[10] В.И. Веттегрень, И.П. Щербаков, Р.И. Мамалимов. ФТТ 58, 2252 (2016).

[11] В.И. Веттегрень, А.В. Пономарев, И.П. Щербаков, Р.И. Мамалимов. ФТТ 59, 931 (2017).

[12] R.B. Bird, W.E. Stewart, E.N. Lightfoot. Transport Phenomena. J. Wiley \& Sons (2007). 905 p.

[13] N.J. Turro. Modern Molecular Photochemistry. University Sci. Columbia University (1991). 628 p.

[14] G.N. Chapman, A.J. Walton. J. Appl. Phys. 54, 5961 (1983).

[15] А.Н. Стрелецкий, А.Б. Пакович, И.Ю. Бутягин. Изв. AH CCCP 50, 3, 477 (1986).

[16] Y. Kawaguchi. Jpn. J. Appl. Phys. 37, 1892 (1998).

[17] M.R. Krbetschek, J. Götze, G. Irmer, U. Rieser, T. Trautmann. Mineral Petrol. 76, 167 (2002).

[18] M.T. Andersen, M. Jain, P. Tidemand-Lichtenberg. J. Appl. Phys. 112, 043507 (2012).

[19] M.R. Baril, D.J. Huntley. J. Phys.: Conden. Matter. 15, 8011 (2003).

[20] T. Trautmann, M.R. Krbetschek, A. Dietrich, W. Stolz. J. Luminescence 85, 45 (1999). 